\title{
Article \\ Halloysite Nanoclay with High Content of Sulfonic Acid-Based Ionic Liquid: A Novel Catalyst for the Synthesis of Tetrahydrobenzo[b]pyrans
}

\author{
Samahe Sadjadi ${ }^{1, *} \mathbb{B}$, Fatemeh Koohestani ${ }^{1}$, Neda Abedian-Dehaghani ${ }^{2}$ and Majid M. Heravi ${ }^{2, *}$ \\ 1 Gas Conversion Department, Faculty of Petrochemicals, Iran Polymer and Petrochemical Institute, \\ Tehran P.O. Box 14975112, Iran; M.tabrizi@ippi.ac.ir \\ 2 Department of Chemistry, School of Physic and Chemistry, Alzahra University, Vanak, \\ Tehran P.O. Box 1993891176, Iran; n.abedian@alzahra.ac.ir \\ * Correspondence: s.sadjadi@ippi.ac.ir (S.S.); mmheravi@alzahra.ac.ir (M.M.H.)
}

check for updates

Citation: Sadjadi, S.; Koohestani, F.; Abedian-Dehaghani, N.; Heravi, M.M. Halloysite Nanoclay with High

Content of Sulfonic Acid-Based Ionic Liquid: A Novel Catalyst for the Synthesis of Tetrahydrobenzo[b]pyrans. Catalysts 2021, 11, 1172. https:// doi.org/10.3390/catal11101172

Academic Editors: Salam Titinchi and Hanna Abbo

Received: 22 August 2021

Accepted: 27 September 2021

Published: 28 September 2021

Publisher's Note: MDPI stays neutral with regard to jurisdictional claims in published maps and institutional affiliations.

Copyright: (c) 2021 by the authors. Licensee MDPI, Basel, Switzerland. This article is an open access article distributed under the terms and conditions of the Creative Commons Attribution (CC BY) license (https:// creativecommons.org/licenses/by/ $4.0 /)$.

\begin{abstract}
One of the main drawbacks of supported ionic liquids is their low loading and consequently, low activity of the resultant catalysts. To furnish a solution to this issue, a novel heterocyclic ligand with multi imine sites was introduced on the surface of amino-functionalized halloysite support via successive reactions with 2,4,6-trichloro-1,3,5-triazine and 2-aminopyrimidine. Subsequently, the imine sites were transformed to sulfonic acid-based ionic liquids via reaction with 1,4-butanesultone. Using this strategy, high loading of ionic liquid was loaded on halloysite nanoclay. The supported ionic liquid was then characterized with XRD, SEM, TEM, EDS, FTIR, BET, TGA and elemental mapping analysis and utilized as a metal-free Brønsted acid catalyst for promoting one-pot reaction of aldehydes, dimedone and malononitrile to furnish tetrahydrobenzo[ $b]$ pyrans. The catalytic tests confirmed high performance of the catalyst. Moreover, the catalyst was stable upon recycling.
\end{abstract}

Keywords: halloysite; ionic liquid; catalyst; tetrahydrobenzo[b]pyrans

\section{Introduction}

Considering the importance of environmental concerns, development of green methodologies for the synthesis of chemicals has gained growing attention. In this regard, use of natural materials for the preparation of catalysts is a hot research topic [1-5]. On the other hand, metal-free catalysts have been introduced as environmentally benign catalysts. One class of metal-free catalysts that has broad applications is ionic liquids (ILs). These compounds are defined as organic salts [6-10] that consist of organic cations [11-14]. As these compounds benefit from outstanding features $[15,16]$, such as low-toxicity and high electric conductivity, they can be applied both as catalysts and solvents. More importantly, the features of ILs can be readily tuned by altering their cations and anions [12,17-19]. In recent years, development of state-of-the art ILs, such as bio-based ILs and chiral ILs expanded the utilities of this class of compounds $[13,20]$. One of the advances in the field of ILs is heterogenation of ILs through their stabilization on supporting materials. Among various potential supports, clays have received increasing interest. One of these clays is halloysite nanoclay (Hal) [21-23] that is dioctahedral 1:1 clay mineral with tubular morphology [24-31]. The outstanding performance of this clay [32,33] as a support has induced many studies and to date [34,35], various catalytic species have been stabilized on Hal. Noteworthy, not only Hal exterior surface can be decorated with catalytic species, but also Hal lumen can be targeted for embedding the catalytic species. Other features of Hal that render it a potential candidate for the catalysis is its electrically charged surfaces [36-38]. In fact, the interior and exterior surfaces of Hal are oppositely charged. Furthermore, both Hal surfaces can be readily functionalized through conventional chemical reactions [39-41]. Introduction of the functional groups on Hal improves its features as a supporting mate- 
rial and leads to the preparation of heterogeneous catalysts with improved activity and recyclability $[42,43]$.

To prepare supported ILs, two strategies can be utilized. In one strategy, IL with proper functional group can be prepared separately and, then immobilized on a support, while in another method, IL can be grown on the supporting material step-wisely [11-14]. In both methods, the loading of IL on the supporting materials is mostly low. This can be due to the nature of the support or unsuitable supporting procedure. Hence, development of supported ILs with high loading of ILs is of great importance [44].

Tetrahydrobenzo[b]pyran derivatives are heterocycles with biological and pharmaceutical properties [45-47]. Conventionally, these heterocycles can be synthesized through catalytic Knoevenagel condensation [48-50]. Considering the importance of this class of heterocycles, to date myriad catalysts have been devised for promoting their synthesis [51-54]. Despite considerable advances, some methodologies suffer from some drawbacks, such as usage of toxic solvents, sever condition, moderate yields and formation of waste.

In the continuation of our studies on the catalysts, we have studied metal-free catalysts that have been achieved through immobilization of ILs on naturally occurring materials [55,56]. In this context, we wish to introduce a new Brønsted acid catalyst that has been prepared through covalent conjugation of high loading of sulfonic acid-based IL on Hal nanoclay, Figure 1. The catalyst, Hal-Py-IL, has been characterized and its catalytic activity and recyclability for the synthesis of $4 H$-benzo[b]pyrans were investigated.

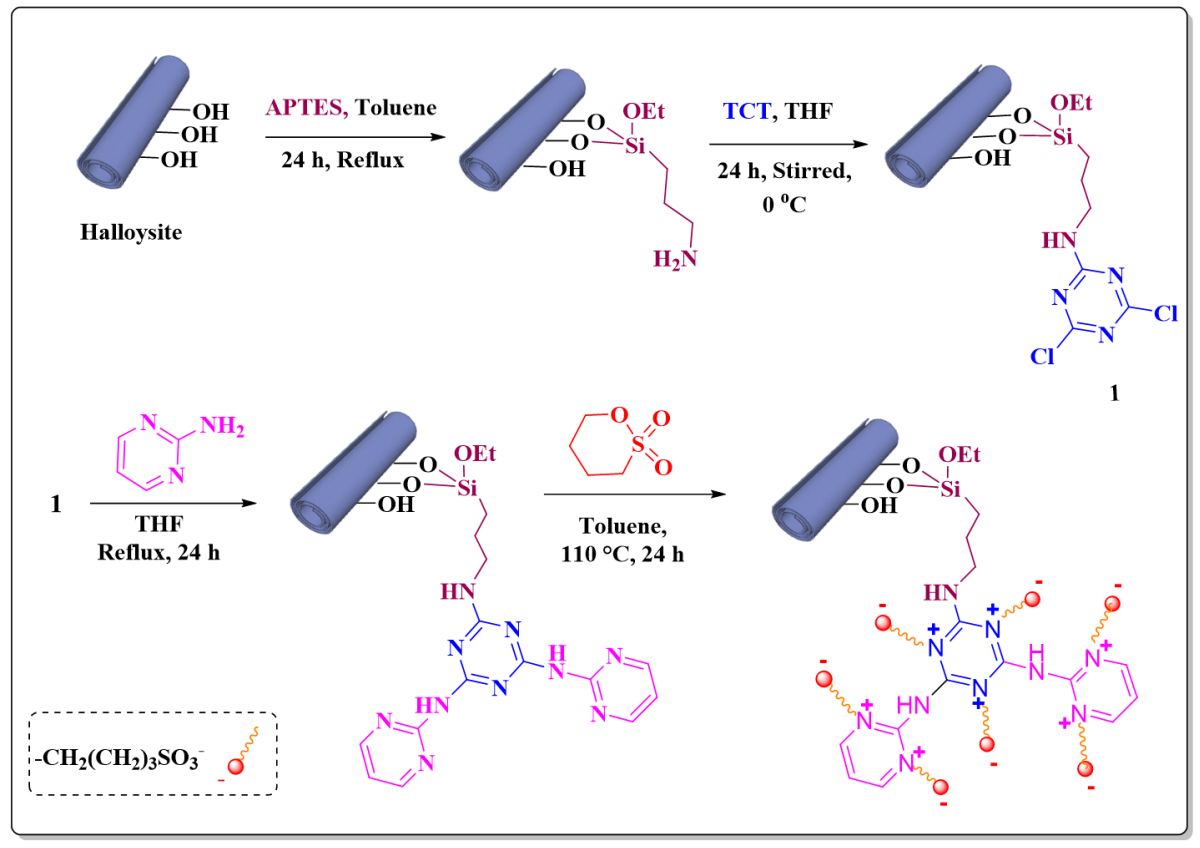

Figure 1. Procedure for the preparation of Hal-Py-IL.

\section{Results and Discussion}

\subsection{Catalyst Characterization}

The as-prepared Hal-Py-IL was then characterized. The first feature of the catalyst that has been evaluated was its morphology. In Figure 2, two SEM images of Hal-Py-IL are depicted. As illustrated, the nano tubes of Hal can be discerned in the SEM images. This fact inferred that tubes of Hal did not collapse upon introduction of Py-IL. Moreover, on Hal tubes, small aggregates can be observed that can be ascribed to Py-IL. 

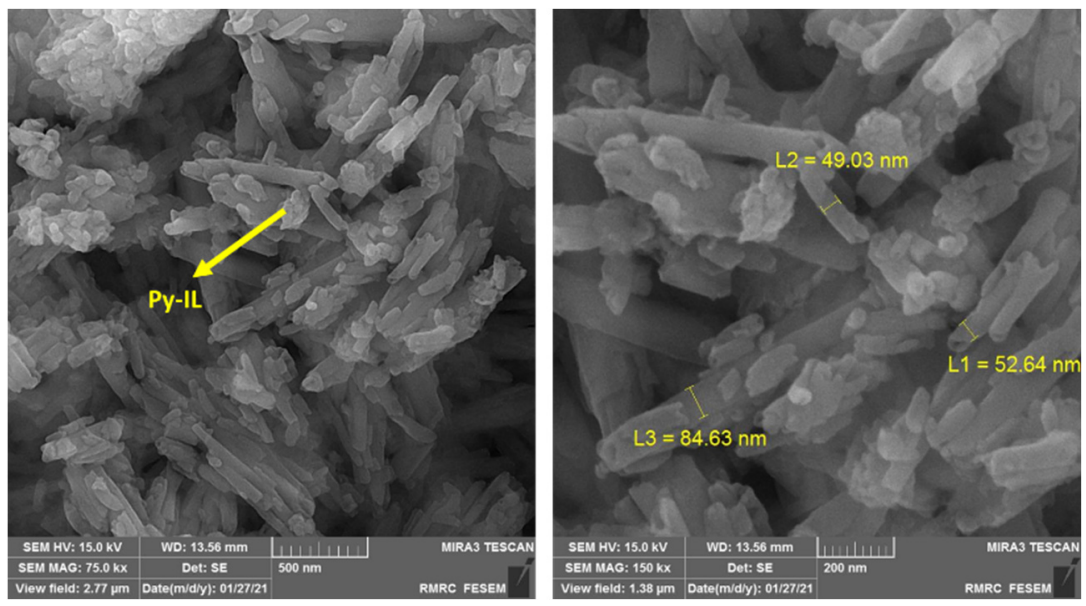

Figure 2. SEM images of Hal-Py-IL.

In Figure 3, the TEM image of Hal-Py-IL is illustrated. As shown, Hal tubes are detected in the TEM image of Hal-Py-IL, implying the stability of Hal structure upon functionalization. Furthermore, in some parts, the thickening of Hal tubes can be observed. This is related to the growth of Py-IL on Hal.

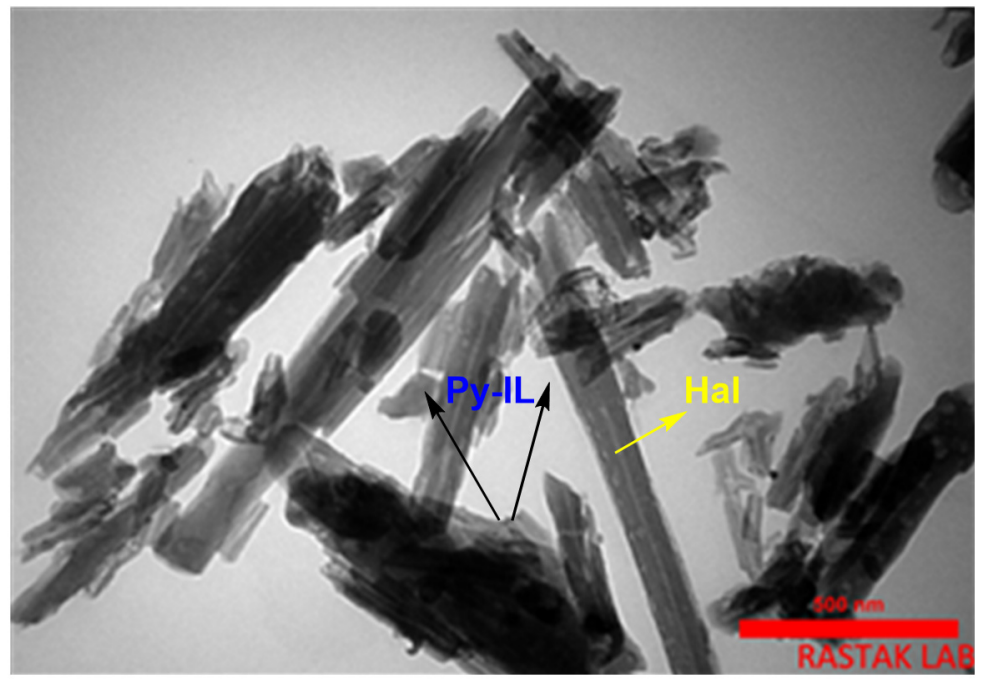

Figure 3. TEM image of Hal-Py-IL.

To further affirm the conjugation of Py-IL moiety on Hal clay, EDS analysis was conducted. The result, depicted in Figure 4, implied that C, N, O, Al, Si and S atoms are present in the framework of Hal-Py-IL. Although EDS analysis is not sufficient for affirming the structure of Hal-Py-IL, observation of $\mathrm{S}$ atom that can be indicative of $\left(-\mathrm{SO}_{3}{ }^{-}\right)$, as well as $\mathrm{C}$ and $\mathrm{N}$ atoms established the presence of Py-IL. Moreover, the absence of $\mathrm{Cl}$ atom can indicate successful substitution reaction between TCT and 2-aminopyrimidine. Furthermore, to shed light into the dispersion of Py-IL, elemental mapping analysis of Hal-Py-IL was conducted. As shown in Figure 4, S, C and N atoms are dispersed uniformly, implying that Py-IL was homogeneously formed on Hal.

Hall-Py-IL was also characterized via XRD analysis, Figure 5. In this context, XRD patterns of both Hal-Py-IL and Hal were obtained and compared. The comparison of the two X-ray diffraction patterns, Figure 5, inferred that all of the bands of Hal are present in the XRD pattern of Hal-Py-IL. However, their intensities significantly decreased. According to the literature, this issue can be indicative of incorporation of Py-IL [57]. 

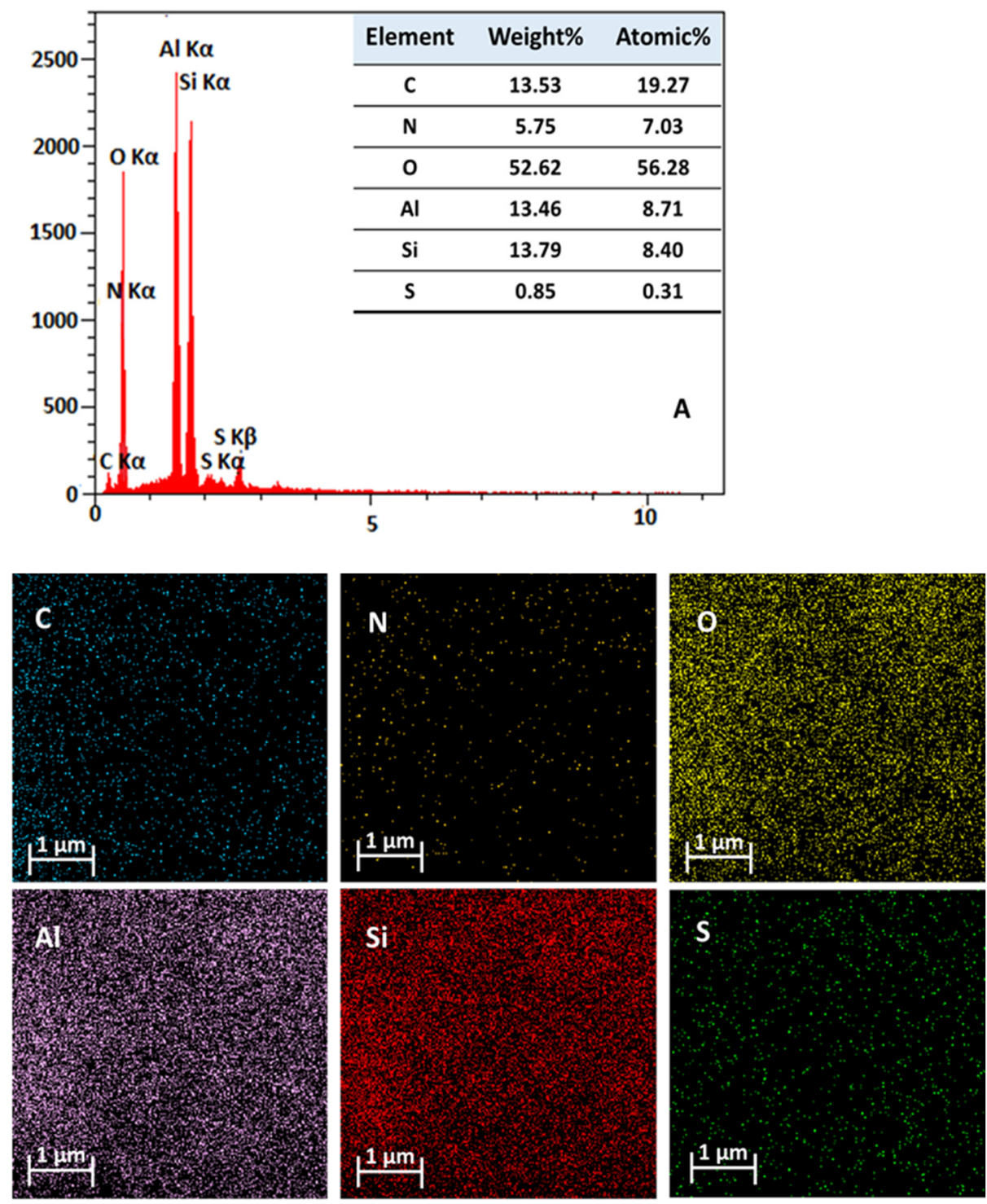

B

Figure 4. (A) EDS and (B) elemental mapping analyses of Hal-Py-IL.

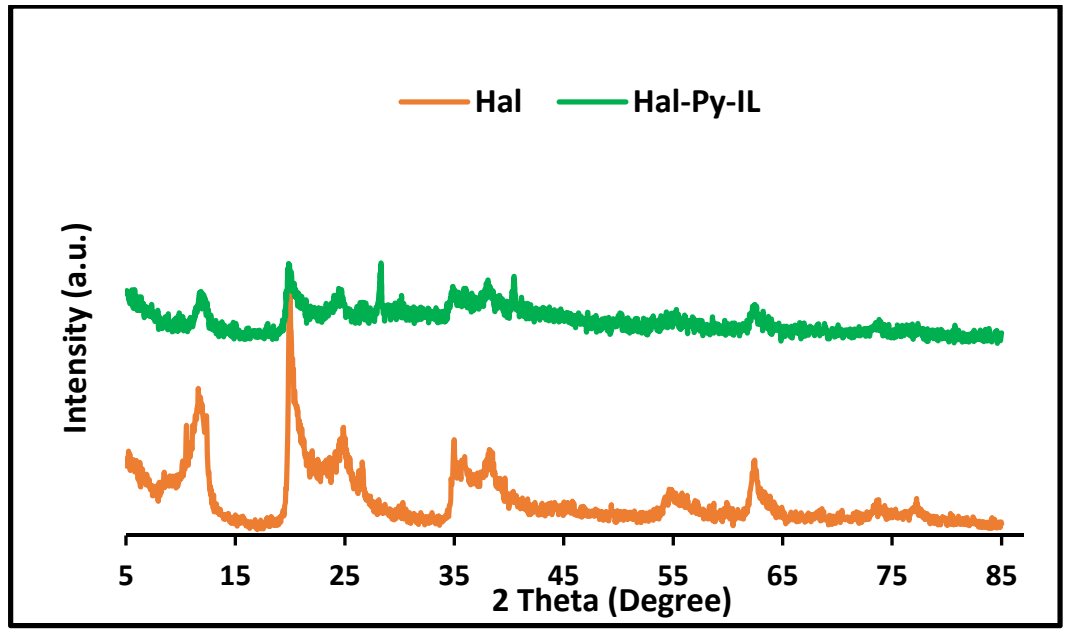

Figure 5. XRD patterns of Hal and Hal-Py-IL. 
In Figure 6, the comparison of the recorded FTIR spectra of Hal, Hal-TCT, Hal-TCT-Py, Hal-Py-IL is presented. According to the literature [42], the absorbance bands of Hal can be listed as the bands at $1054 \mathrm{~cm}^{-1}$ (Si-O), $3696 \mathrm{~cm}^{-1}$ and $3623 \mathrm{~cm}^{-1}$ (inner $-\mathrm{OH}$ ), and $536 \mathrm{~cm}^{-1}$ (Al-O-Si). These characteristic bands can be observed in the FTIR spectra of Hal-TCT, Hal-TCT-Py and Hal-Py-IL, confirming the fact that Hal structure was stable in the course of introduction of the organic species. The comparison of the FTIR spectra of Hal and three other samples established that in the Hal-TCT, Hal-TCT-Py and Hal-Py-IL spectra, a new band at $1660-1687 \mathrm{~cm}^{-1}$ is observable. This absorbance band is ascribed to the $-\mathrm{C}=\mathrm{N}$ functionality of TCT and 2-aminopyrimidine. Furthermore, the absorbance band at $2931 \mathrm{~cm}^{-1}$ in the FTIR spectrum of Hal-Py-IL is due to $-\mathrm{CH}_{2}$ and proves conjugation of 1,4-butanesultone.

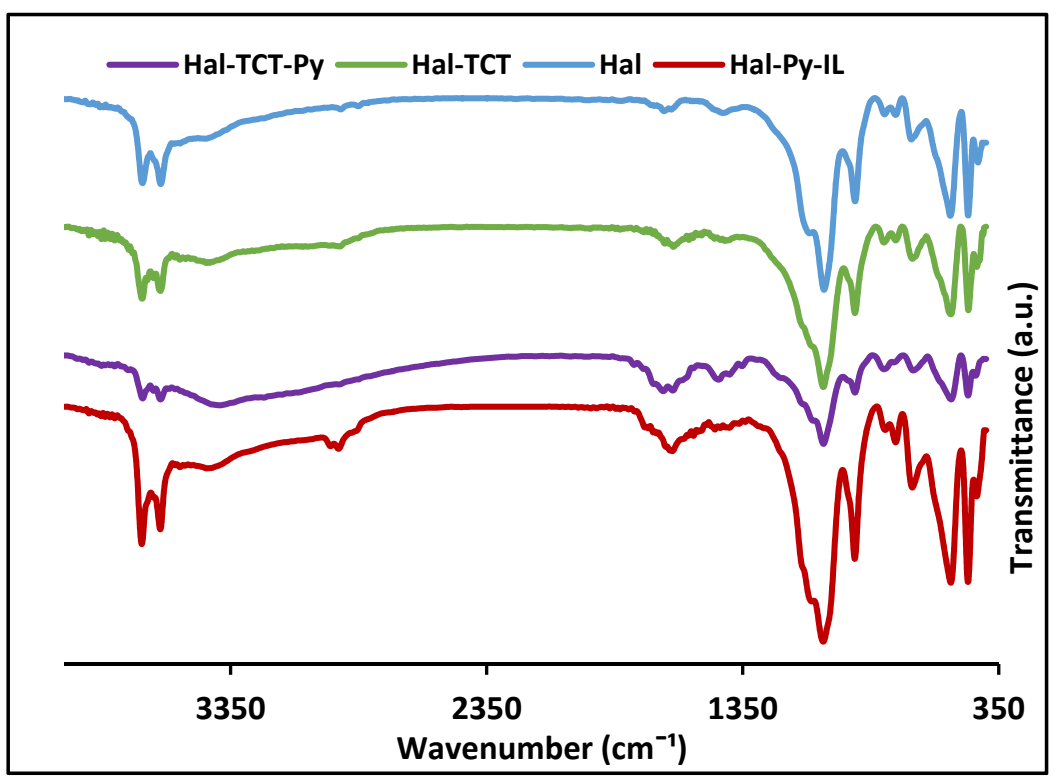

Figure 6. FTIR spectra of Hal, Hal-TCT, Hal-TCT-Py, Hal-Py-IL.

To validate conjugation of the organic moiety, TG analysis of Hal, Hal-TCT-Py and Hal-Py-IL was conducted and the obtained TG curves were compared, Figure 7. As shown, in Figure 7, in Hal thermogram, two weight loss steps can be discerned that are assigned to the loss of $\mathrm{H}_{2} \mathrm{O}$ and dehydroxylation of $\mathrm{Hal}\left(\right.$ at $\left.480^{\circ} \mathrm{C}\right)$ [58,59]. In the case of Hal-TCT-Py, apart from the aforementioned weight losses, a new loss occurred at $340^{\circ} \mathrm{C}$ that is assigned to the degradation of TCT-Py. According to the TGA, the loading of TCT-Py was calculated as $18 \mathrm{wt}$. \%. Comparison of the thermograms of the catalyst with that of Hal-TCT-Py implied that the content of the loaded 1,4-butanesultone was $3 \mathrm{wt}$. \%.

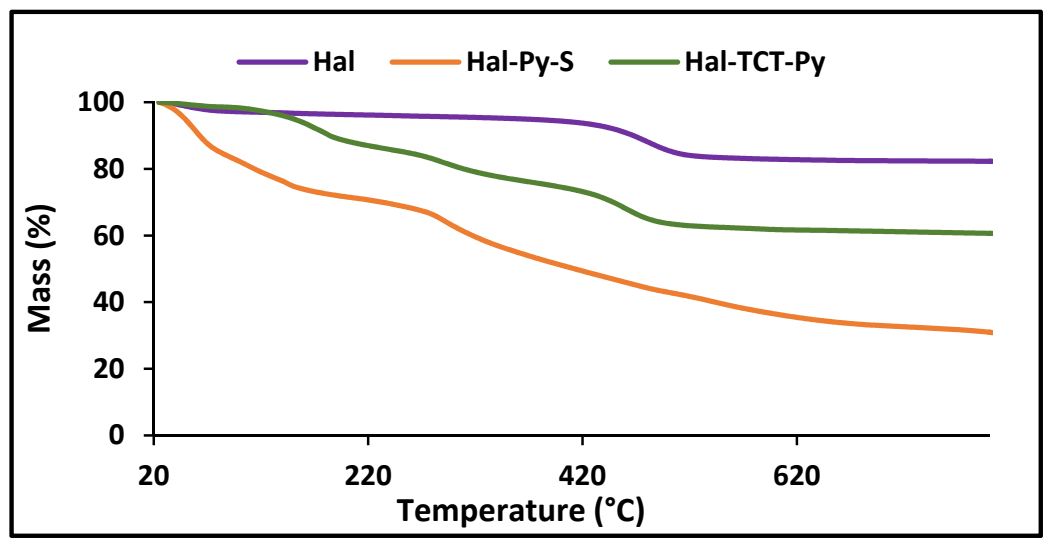

Figure 7. TG thermograms of Hal, Hal-TCT-Py, Hal-Py-IL. 
BET analysis of Hal-Py-IL and Hal was conducted and the surface properties of the two samples have been compared. As illustrated in Figure 8, the $\mathrm{N}_{2}$ adsorption-desorption isotherms of both Hal-Py-IL and Hal are of type II. Regarding the specific surface area, it was found that by growth of Py-IL on Hal, the specific surface area decreased from 51 to $5.2 \mathrm{~m}^{2} \cdot \mathrm{g}^{-1}$. This significant decrease of this value can establish coverage of Hal with Py-IL.

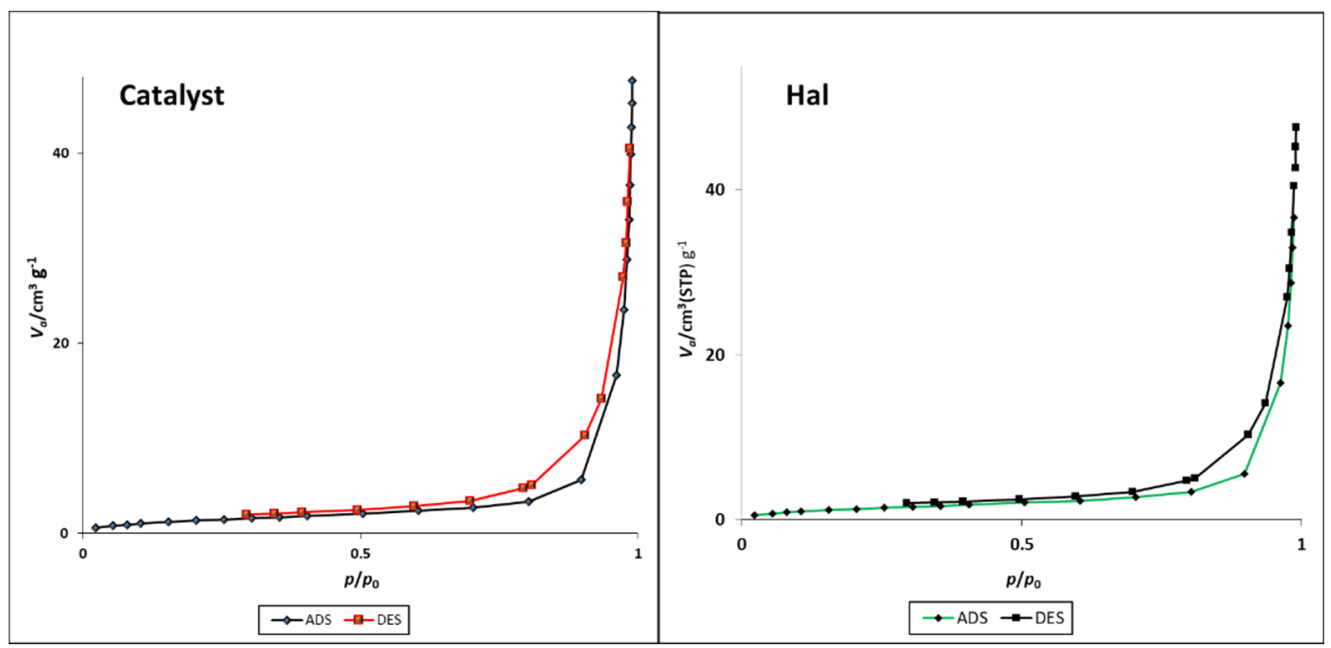

Figure 8. $\mathrm{N}_{2}$ adsorption-desorption isotherms of Hal (right) and Hal-Py-IL (left).

\subsection{Activity}

In the next section, the activity of the as-prepared Hal-Py-IL was evaluated. In this regard, the performance of the catalyst for the preparation of $4 H$-benzo $[b]$ pyrans through one-pot reaction of aldehyde, malononitrile and dimedone was appraised, Figure 9.

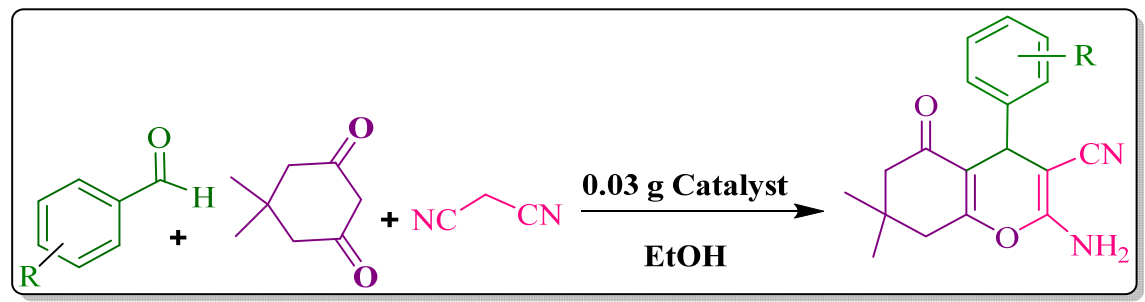

Figure 9. Preparation of $4 H$-benzo[b] pyrans.

\subsubsection{Optimization of Reaction Condition}

First, a model $4 \mathrm{H}$-benzo[b] pyran, derived from reaction of 4-nitrobenzaldehyde, malononitrile and dimedone, was selected to optimize the effective reaction parameters and find the best reaction condition. In this respect, the influence of the reaction solvent was first examined by conducting the reaction in $\mathrm{EtOH}, \mathrm{H}_{2} \mathrm{O}$ and $\mathrm{H}_{2} \mathrm{O}$ : $\mathrm{EtOH}$ (1:2). Among the studied solvents, EtOH was recognized as the most efficient solvent, Table 1. Next, the model synthesis was conducted in the presence of different dosage of Hal-Py-IL (20-40 mg). It was affirmed that this is an influential factor. In fact, increasing of the catalyst content from 20 to $30 \mathrm{mg}$ led to the increase of the yield of the reaction. However, further increment to $40 \mathrm{mg}$ was not effective. Hence, $30 \mathrm{mg}$ of Hal-Py-IL was selected as the optimum catalyst dosage. Finally, the reaction temperature was optimized by varying the temperature (ambient temperature to $60^{\circ} \mathrm{C}$ ). The results, Table 1 , indicated that increasing the temperature to $50{ }^{\circ} \mathrm{C}$ resulted in accelerating the reaction rate and increase of the yield of the reaction. Notably, elevating the reaction temperature to $60^{\circ} \mathrm{C}$ had no significant effect. Considering these results, the optimum condition for the reaction was found to be use of $30 \mathrm{mg}$ of Hal-Py-IL in EtOH at $50{ }^{\circ} \mathrm{C}$. 
Table 1. Optimization of the reaction variables for the model reaction.

\begin{tabular}{cccccc}
\hline Entry & Hal/Py-IL (mg) & Solvent & Temp. $\left({ }^{\circ} \mathbf{C}\right)$ & Time (h) & Yield (\%) \\
\hline 1 & 20 & $\mathrm{H}_{2} \mathrm{O}$ & r.t. & 2 & 50 \\
2 & 20 & $\mathrm{H}_{2} \mathrm{O}: \mathrm{EtOH}$ & r.t. & 2 & 50 \\
3 & $(1: 2)$ & r.t. & 2 & 60 \\
4 & 20 & EtOH & 40 & 2 & 75 \\
5 & 20 & EtOH & 50 & 1.5 & 80 \\
6 & 20 & EtOH & 60 & 1.5 & 80 \\
7 & 20 & EtOH & 50 & 1.5 & 100 \\
8 & 30 & EtOH & 50 & 1.5 & 100 \\
\hline
\end{tabular}

\subsubsection{Comparison of the Activity of Hal-Py-IL with Control Catalysts}

To disclose the beneficial effect of conjugation of the catalyst components, the catalytic activity of Hal-Py-IL for promoting the model reaction under the optimum condition was compared with some control catalysts. First, the catalytic activity of Hal for the model reaction was examined. As tabulated in Table 2, Hal exhibited low catalytic activity and furnish the desired product in $25 \%$ yield after $3 \mathrm{~h}$. Similarly, the catalytic activity of Hal-N (obtained from reaction of $\mathrm{Hal}$ and APTES), Hal-TCT (prepared from reaction of Hal-N with TCT) and Hal-Py (prepared from reaction of Hal-TCT with 2-aminopyrimidine) was also examined for the model reaction. As listed in Table 2, functionalization of Hal with APTES, TCT and 2-aminopyrimidine did not affect the catalytic activity of the resultant catalyst.

Table 2. Comparison of the activity of Hal-Py-IL with some control catalysts.

\begin{tabular}{cccc}
\hline Entry & Catalyst & Time (h:min) & Yield (\%) \\
\hline 1 & Hal & 3 & 25 \\
2 & Hal-N & 3 & 25 \\
3 & Hal-TCT & 3 & 25 \\
4 & Hal-Py & 3 & 25 \\
5 & Py & 3 & 15 \\
6 & Py-IL & 2 & 87 \\
7 & Hal-Py-IL & $1: 5$ & 100 \\
8 & SA & $2: 5$ & 80 \\
\hline
\end{tabular}

Next, the catalytic activity of Py (prepared from reaction of TCT and 2-aminopyrimidine) was appraised. This control catalyst showed low catalytic activity.

Py-IL was also prepared through successive reaction of TCT with 2-aminopyrimidine and 1,4-butanesultone and its catalytic activity was examined for the model reaction. It was found that the catalytic activity of Py-IL was slightly lower than that of Hal-Py-IL. More precisely, Py-IL promoted the reaction to give the desired product in $87 \%$ yield. In fact, the catalytic activity of Py-IL is due to the instinct activity of IL. Higher activity of Hal-Py-IL can be ascribed to the synergistic effect between Hal and Py-IL.

Finally, the catalytic activity of sulfonic acid (SA), prepared from reaction of 2aminopyrimidine with 1,4-butanesultone was examined for the model reaction. As shown in Table 2, the activity of SA was lower than that of Hal-Py-IL and furnished the product in $80 \%$ after $65 \mathrm{~min}$.

These results confirmed that conjugation of Hal and Py-IL is beneficiary for the catalytic activity.

\subsubsection{Generality}

Next, the substrate scope of the present methodology was appraised. In this context, various aldehydes were applied for the synthesis of $4 H$-benzo[b] pyrans. The results, listed in Table 3, approved that Hal-Py-IL can efficiently promote the reaction of various substrates to furnish the corresponding products in high yields. It is worth noting that the reaction yield for the aldehydes with electron-withdrawing groups was slightly higher 
than that of the substrates with electron-donating groups. Moreover, it was found that heterocyclic aldehydes underwent the reaction to give the products in high yields.

Table 3. Synthesis of $4 H$-benzo[b] pyrans ${ }^{a}$.

\begin{tabular}{ccccc}
\hline Entry & Aldehyde & $\begin{array}{c}\text { Time } \\
\text { (h:min) }\end{array}$ & $\begin{array}{c}\text { Conversion } \\
\text { (\%) }\end{array}$ & $\begin{array}{c}\text { Yield } \\
\text { (\%) }\end{array}$ \\
\hline 1 & Benzaldehyde & 2 & 90 & 90 \\
2 & 4-Nitrobenzaldehyde & $1: 5$ & 100 & 100 \\
3 & 3-Nitrobenzaldehyde & $1: 5$ & 95 & 95 \\
4 & 2-Nitrobenzaldehyde & $1: 5$ & 100 & 100 \\
5 & 4-Chlorobenzaldehyde & $1: 5$ & 95 & 95 \\
6 & 2-Chlorobenzaldehyde & $1: 5$ & 95 & 95 \\
7 & 2, 6-Di-chlorobenzaldehyde & $1: 5$ & 97 & 90 \\
8 & 4-Methoxybenzaldehyde & $2: 5$ & 95 & 88 \\
9 & 4-Hydroxybenzaldehyde & 2 & 96 & 90 \\
10 & 4-Bromobenzaldehyde & $1: 5$ & 95 & 95 \\
11 & 4-Cyanobenzaldehyde & $1: 5$ & 96 & 90 \\
12 & 4-(Dimethylamino)benzaldehyde & $2: 5$ & 85 & 74 \\
13 & 2-Naphthalenecarboxaldehyde & $2: 5$ & 80 & 61 \\
14 & Furfural & 2 & 90 & 81 \\
15 & 3-Pyridinecarboxaldehyde & 2 & 89 & 75 \\
16 & Thiophene-2-carbaldehyde & $2: 5$ & 88 & 72 \\
\hline
\end{tabular}

a Reaction condition: aldehyde $(1 \mathrm{mmol})$, malononitrile $(1 \mathrm{mmol})$, dimedone $(1 \mathrm{mmol})$, catalyst $(30 \mathrm{mg})$, at $50{ }^{\circ} \mathrm{C}$ in $\mathrm{EtOH}$.

\subsubsection{Reaction Mechanism}

In Figure 10, the reaction mechanism for the synthesis of $4 H$-benzo[b] pyrans under Hal-Py-IL catalysis is depicted. As shown, Hal-Py-IL can activate the aldehyde and malononitrile and promotes their Knoevenagel condensation to furnish compound 1. In the next step, Michael addition of compound 1 and enolate form of dimedone forms intermediate 2. Next, nucleophilically attack of enolate oxygen to nitrile group leads to the formation of a cyclic intermediate, compound 3, which tolerates tautomeric proton shift to furnish $4 H$-benzo[b] pyran.

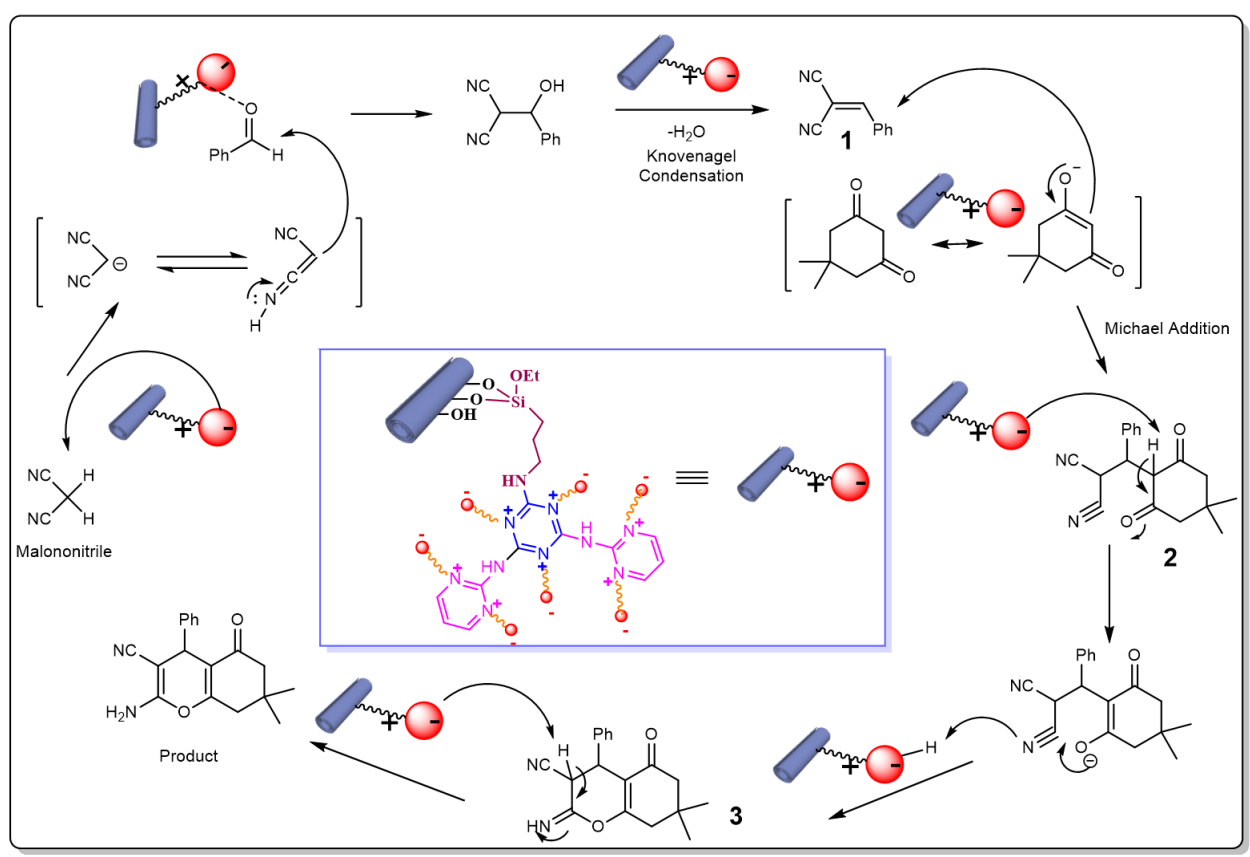

Figure 10. Plausible mechanism of preparation of $4 H$-benzo[b] pyrans under Hal-Py-IL catalysis. 


\subsubsection{Comparative Study}

To investigate whether the efficiency of Hal-Py-IL for the preparation of $4 H$-benzo[b] pyrans is comparable with other reported catalysts, a comparative study has been conducted, Table 4 . As tabulated, various catalysts, ranging from magnetic catalysts to porous polymer have been reported for catalyzing this organic synthesis. Comparison of the catalytic performance of the summarized catalysts indicated that the catalytic activity of Hal-Py-IL is comparable with the previous catalysts.

Table 4. Comparison of the activity of Hal-Py-IL with other catalysts for the synthesis of the model product.

\begin{tabular}{|c|c|c|c|c|c|c|c|}
\hline Entry & Catalyst & $\begin{array}{l}\text { Catalyst } \\
\text { Amount }\end{array}$ & Solvent & Condition & Time (min) & Yield (\%) & Ref. \\
\hline 1 & $\mathrm{NH}_{4} \mathrm{H}_{2} \mathrm{PO}_{4} / \mathrm{Al}_{2} \mathrm{O}_{3}$ & $0.03 \mathrm{~g}$ & - & Solvent-free & 30 & 92 & {$[60]$} \\
\hline 2 & $\mathrm{Ce}_{1} \mathrm{Mg}_{0.6} \mathrm{Zr}_{0.4} \mathrm{O}_{2}$ & $0.2 \mathrm{~g}$ & $\mathrm{EtOH}$ & Reflux & 40 & 90 & [61] \\
\hline 3 & $\mathrm{mPMF}{ }^{\mathrm{a}}$ & $0.02 \mathrm{~g}$ & - & $\begin{array}{l}\text { Ball milling, } \\
\text { r.t. }\end{array}$ & 60 & 92 & {$[62]$} \\
\hline 4 & $\begin{array}{c}\mathrm{Fe}_{3} \mathrm{O}_{4} @ \mathrm{SiO}_{2} \text {-guanidine-poly } \\
\text { acrylic acid }\end{array}$ & $0.05 \mathrm{~g}$ & $\mathrm{H}_{2} \mathrm{O}$ & $70{ }^{\circ} \mathrm{C}$ & 20 & 98 & [63] \\
\hline 5 & Aminopropylated silica gel & $10 \mathrm{~mol} \%$ & $\mathrm{H}_{2} \mathrm{O}$ & $70{ }^{\circ} \mathrm{C}$ & 45 & 90 & {$[64]$} \\
\hline 6 & $\mathrm{MnFe}_{2} \mathrm{O}_{4} @ \mathrm{SiO}_{2} \mathrm{NH}-\mathrm{NH}_{2}-\mathrm{PTA}^{\mathrm{b}}$ & $0.04 \mathrm{~g}$ & - & $80{ }^{\circ} \mathrm{C}$ & 25 & 95 & [65] \\
\hline 7 & Nano $\mathrm{ZnO}$ & $10 \mathrm{~mol} \%$ & $\begin{array}{c}\mathrm{EtOH}: \mathrm{H}_{2} \mathrm{O} \\
(1: 1)\end{array}$ & r.t. & 180 & 91 & [66] \\
\hline 8 & $\mathrm{CuO}-\mathrm{CNS}^{\mathrm{c}}$ & $15 \mathrm{w} \%$ & $\mathrm{H}_{2} \mathrm{O}$ & r.t. & 20 & 90 & [67] \\
\hline 9 & SB-DABCO $^{\mathrm{d}}$ & $0.06 \mathrm{~g}$ & $\mathrm{EtOH}$ & r.t. & 20 & 90 & [68] \\
\hline 10 & Hal-Py-IL & $0.03 \mathrm{~g}$ & $\mathrm{EtOH}$ & $50{ }^{\circ} \mathrm{C}$ & 90 & 100 & $\begin{array}{l}\text { This } \\
\text { Work }\end{array}$ \\
\hline
\end{tabular}

a: Nitrogen-rich porous organic polymer. ${ }^{\mathrm{b}}: \mathrm{MnFe}_{2} \mathrm{O}_{4} @ \mathrm{SiO}_{2} @ \mathrm{NHPhNH}_{2}$-phosphotungstic acid. ${ }^{\mathrm{c}}$ : $\mathrm{CuO}$ on cellulose nanocrystals. ${ }^{\mathrm{d}}$ : Silica bonded n-propyl-4-aza-1-azoniabicyclo[2.2.2]octane chloride.

\subsection{Catalyst Recyclability}

The recyclability of Hal-Py-IL was appraised under the optimized condition for the multi-component condensation reaction of 4-nitrobenzaldehyde, malononitrile and dimedone. In this regard, after completion of the first run of the model reaction, Hal-Py-IL was filtered off, washed with hot $\mathrm{EtOH}$, dried and used for the next run of the same condensation reaction. The recovered Hal-Py-IL was sequentially reused and the yields of the reactions were calculated for eight reaction runs, Figure 11. As illustrated in Figure 11, reuse of Hal-Py-IL for the second run did not cause any decrement of the activity of the catalyst. However, using Hal-Py-IL for the third time led to slight loss of the activity. Further reuse also induced slight decrease of the catalytic activity and after eighth run the yield of the reaction was $80 \%$.

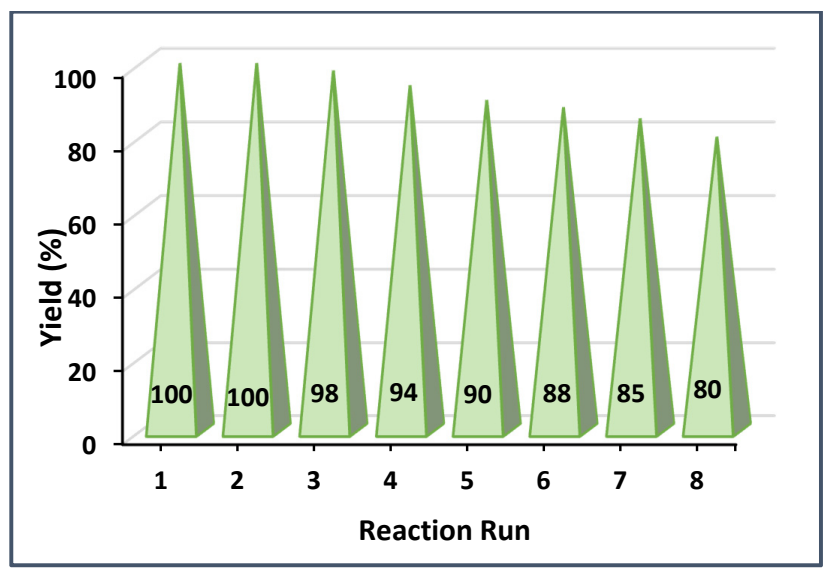

Figure 11. Reusability of Hal-Py-IL for the preparation of $4 H$-benzo[b] pyrans for the reaction of 4-nitrobenzaldehyde, malononitrile, dimedone at $50{ }^{\circ} \mathrm{C}$ in $\mathrm{EtOH}$. 
The reused Hal-Py-IL after eight runs was analyzed via FTIR spectroscopy and the recorded FTIR spectrum was compared with spectrum of fresh Hal-Py-IL. As depicted in Figure 12, FTIR spectrum of the reused Hal-Py-IL is identical to that of the fresh one and contains all of the absorbance bands of the fresh catalyst, implying that reusing of Hal-Py-IL did not induce structural collapse and Hal-Py-IL was stable in the course of recycling.

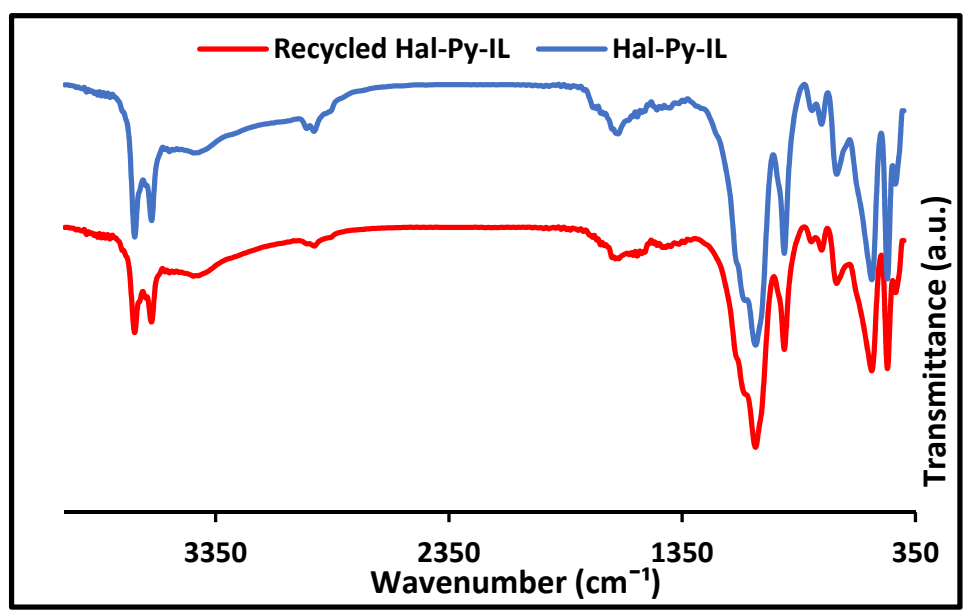

Figure 12. The FTIR spectra of fresh and reused Hal-Py-IL after eight runs.

\section{Materials and Methods}

The used reagents and solvents for the preparation of the catalyst included Hal, 3(aminpropyl)-triethoxysilane (APTES), 2-aminopyrimidine, 1,4-butanesultone, potassium carbonate $\left(\mathrm{K}_{2} \mathrm{CO}_{3}\right)$, 2,4,6-trichloro-1,3,5-triazine (TCT), tetrahydrofuran (THF), toluene, all was purchased from Sigma-Aldrich. The chemicals that have been applied for the evaluation of the catalytic performance of the catalyst included dimedone, malononitrile, ethanol (EtOH), aldehydes. All was received from Sigma-Aldrich (Germany, Taufkirchen).

In order to confirm the formation of the designed catalyst, several analyses, including, thermo gravimetric analysis (TGA), X-ray diffraction (XRD), scanning electron microscope (SEM), Fourier transform infrared (FTIR), energy dispersive spectroscopy (EDS) and elemental mapping analyses were conducted. The technical data of the applied apparatuses are as follow: BRUKER TENSOR 35 (Germany, Berlin) was used for performing FTIR spectroscopies using $\mathrm{KBr}$ pellet. Using METTLER TOLEDO thermogravimetric analysis instrument (model Leicester, Leicester, UK) with heating rate of $10^{\circ} \mathrm{C} / \mathrm{min}$, the $\mathrm{TG}$ analyses were carried out under $\mathrm{N}_{2}$ atmosphere. Siemens, D5000 instrument (Karlsruhe, Germany) with graphite monochromatic $\mathrm{Cu}-\mathrm{K} \alpha$ was applied for conducting XRD analysis. SEM /EDS and elemental mapping analyses were performed on MIRA 3 TESCAN-XMU (Kohoutovice, Czech Republic). Transmission electron microscopy (TEM) was conducted by using Philips CM30300Kv (Beaverton, OR, USA) field emission transmission electron microscope. The specific surface area of the catalyst and Hal were evaluated by Brunauer-Emmet-Teller (BET) via Belsorp Mini II (BEL Japan, Inc., Osaka, Japan). Pre-heating was conducted at $100{ }^{\circ} \mathrm{C}$ for $3 \mathrm{~h}$.

\subsection{Catalyst Fabrication}

\subsubsection{Hal Functionalization with APTES: Hal-N}

To functionalize Hal with APTES, suspension of Hal $(4 \mathrm{~g})$ in toluene $(80 \mathrm{~mL})$ was ultrasounded (power of $230 \mathrm{~W}$ for $10 \mathrm{~min}$ ) to furnish a homogenized suspension. Afterwards, APTES $(4.5 \mathrm{~mL})$ was added to the as-prepared Hal suspension and the obtained mixture was refluxed overnight at $100{ }^{\circ} \mathrm{C}$ under Ar atmosphere. At the end of the reaction, the solid was separated, washed with dry toluene and dried in oven at $80^{\circ} \mathrm{C}$ for 1 day. 


\subsubsection{Preparation of Hal-TCT}

In order to prepare Hal-TCT, Hal-N $(3 \mathrm{~g})$ and $\mathrm{K}_{2} \mathrm{CO}_{3}(1 \mathrm{mmol})$ as a base were dispersed in THF ( $40 \mathrm{~mL}$ ) and subjected to ultrasonic waves (power of $230 \mathrm{~W}$ ) for $10 \mathrm{~min}$. Then, the homogenized mixture was stirred in ice bath for $30 \mathrm{~min}$. Afterwards, a solution of TCT ( $8 \mathrm{mmol}$ in $10 \mathrm{~mL}$ THF) was added and the mixture was kept under stirring at $0{ }^{\circ} \mathrm{C}$ for 1 day. At the end, the precipitate was collected via conventional filtration, rinsed with THF and dried at $60^{\circ} \mathrm{C}$.

\subsubsection{Preparation of Hal-Py}

Suspension of Hal-TCT $(3 \mathrm{~g})$ in THF $(40 \mathrm{~mL})$ was well dispersed by using ultrasonic irradiation (power of $230 \mathrm{~W}$ for $10 \mathrm{~min}$ ). Then, a solution of 2-aminopyrimidine (16 mmol in $10 \mathrm{~mL}$ THF) was injected to the Hal-TCT suspension. Subsequently, the obtained mixture was refluxed overnight at $70{ }^{\circ} \mathrm{C}$ under inert gas atmosphere. Afterwards, the solid was filtered, rinsed with THF repeatedly and dried at $60^{\circ} \mathrm{C}$.

\subsubsection{Introduction of Ionic Liquid: Synthesis of Hal-Py-IL}

In the final step, Hal-Py $(1.5 \mathrm{~g})$ was dispersed in dry toluene $(35 \mathrm{~mL})$ under ultrasonic irradiation (power of $230 \mathrm{~W}$ for $10 \mathrm{~min}$ ). Subsequently, a solution of 1,4-butanesultone $(20 \mathrm{mmol})$ in toluene $(15 \mathrm{~mL})$ was injected into the mentioned suspension in a dropwise manner. The mixture was then refluxed at $110{ }^{\circ} \mathrm{C}$ for $24 \mathrm{~h}$. At the end of the reaction, the precipitate was filtered off, washed with toluene and dried at $70{ }^{\circ} \mathrm{C}$ in oven for $12 \mathrm{~h}$, Figure 1.

\subsection{General Procedure for the Synthesis of $4 H-B e n z o[b] p y r a n$ Derivatives}

To synthesize $4 H$-benzo[b]pyran derivatives, dimedone $(1 \mathrm{mmol})$, malononitrile ( $1 \mathrm{mmol})$, aryl aldehyde $(1 \mathrm{mmol})$ were dissolved in EtOH $(10 \mathrm{~mL})$. Then, Hal-Py-IL $\left(30 \mathrm{mg}\right.$ ) as a catalyst was added to the reaction vessel and the mixture was stirred at $50^{\circ} \mathrm{C}$. At the end of the reaction, which was affirmed by TLC, the reaction mixture was allowed to cool to the room temperature and then Hal-Py-IL was readily filtered via filtration paper. The solvent in reaction vessel was evaporated and the resulting residue was purified with recrystallization from EtOH or column chromatography. The recovered Hal-Py-IL on the other hand, was washed with EtOH several time and dried in oven at $70{ }^{\circ} \mathrm{C}$ overnight. The synthesis of the products was confirmed via FTIR, NMR and Mass spectroscopies (Figures S1-S22).

\section{Conclusions}

A novel sulfonic acid-based IL was grown on Hal surface through successive reactions of Hal-N with TCT, 2-aminopyrimidine and 1,4-butanesultone. This catalyst that benefits from high loading of IL was then characterized and utilized for catalyzing one-pot three component reaction of aldehydes, dimedone and malononitrile to furnish tetrahydrobenzo[b]pyrans. The results affirmed that the catalyst was highly active and could promote reaction of various substrates to furnish the corresponding tetrahydrobenzo[b]pyrans in high yields. Moreover, Hal-Py-IL was highly recyclable and could be recovered and reused for eight consecutive reaction runs with slight loss of the catalytic activity.

Supplementary Materials: The following are available online at https:/ /www.mdpi.com/article/10 .3390 / catal11101172/s1, Figure S1: Figure S1. ${ }^{1}$ HNMR spectrum of 2-amino-4-(4-methoxyphenyl)-7,7dimethyl-5-oxo-5,6,7,8-tetrahydro-4H-chromene-3-carbonitrile, Figure S2. Mass spectrum of 2-amino4-(4-methoxyphenyl)-7,7-dimethyl-5-oxo-5,6,7,8-tetrahydro-4H-chromene-3-carbonitrile, Figure S3. FTIR spectrum of 2-amino-4-(4-methoxyphenyl)-7,7-dimethyl-5-oxo-5,6,7,8-tetrahydro-4H-chromene3-carbonitrile, Figure S4. ${ }^{1}$ HNMR spectrum of 2-amino-4-(4-bromophenyl)-7,7-dimethyl-5-oxo-5,6,7,8tetrahydro-4H-chromene-3-carbonitrile, Figure S5. ${ }^{13} \mathrm{CNMR}$ spectrum of 2-amino-4-(4-bromophenyl)7,7-dimethyl-5-oxo-5,6,7,8-tetrahydro-4H-chromene-3-carbonitrile, Figure S6. FTIR spectrum of 2amino-4-(4-bromophenyl)-7,7-dimethyl-5-oxo-5,6,7,8-tetrahydro-4H-chromene-3-carbonitrile, Figure $\mathrm{S} 7$. ${ }^{13} \mathrm{CNMR}$ spectrum of 2-amino-7,7-dimethyl-4-(3-nitrophenyl)-5-oxo-5,6,7,8-tetrahydro-4H-chromene- 
3-carbonitrile, Figure S8. Mass spectrum of 2-amino-7,7-dimethyl-4-(3-nitrophenyl)-5-oxo-5,6,7,8tetrahydro- $4 H$-chromene-3-carbonitrile, Figure S9. FTIR spectrum of 2-amino-7,7-dimethyl-4-(3nitrophenyl)-5-oxo-5,6,7,8-tetrahydro- $4 H$-chromene-3-carbonitrile, Figure S10. ${ }^{13} \mathrm{CNMR}$ spectrum of 2-amino-4-(4-hydroxyphenyl)-7,7-dimethyl-5-oxo-5,6,7,8-tetrahydro-4H-chromene-3-carbonitrile, Figure S11. ${ }^{1} \mathrm{HNMR}$ spectrum of 2-amino-4-(4-chlorophenyl)-7,7-dimethyl-5-oxo-5,6,7,8-tetrahydro$4 H$-chromene-3-carbonitrile, Figure S12. FTIR spectrum of 2-amino-4-(4-chlorophenyl)-7,7-dimethyl5-oxo-5,6,7,8-tetrahydro-4H-chromene-3-carbonitrile, Figure S13. Mass spectrum of 2-amino-4-(4chlorophenyl)-7,7-dimethyl-5-oxo-5,6,7,8-tetrahydro- $4 H$-chromene-3-carbonitrile, Figure S14. ${ }^{13} \mathrm{CNMR}$ spectrum of 2-amino-4-(4-chlorophenyl)-7,7-dimethyl-5-oxo-5,6,7,8-tetrahydro-4H-chromene-3-carbonitrile, Figure S15. FTIR spectrum of 2-amino-7,7-dimethyl-5-oxo-4-phenyl-5,6,7,8-tetrahydro-4Hchromene-3-carbonitrile, Figure S16. ${ }^{13} \mathrm{CNMR}$ spectrum of 2-amino-7,7-dimethyl-5-oxo-4-phenyl5,6,7,8-tetrahydro-4H-chromene-3-carbonitrile, Figure S17. ${ }^{1} \mathrm{HNMR}$ spectrum of 2-amino-7,7-dimethyl5-oxo-4-phenyl-5,6,7,8-tetrahydro-4H-chromene-3-carbonitrile, Figure S18. FTIR spectrum of 2amino-7,7-dimethyl-4-(4-nitrophenyl)-5-oxo-5,6,7,8-tetrahydro-4H-chromene-3-carbonitrile, Figure S19. ${ }^{1}$ HNMR spectrum of 2-amino-7,7-dimethyl-4-(4-nitrophenyl)-5-oxo-5,6,7,8-tetrahydro-4H-chromene-3-carbonitrile, Figure S20. Mass spectrum of 2-amino-7,7-dimethyl-4-(4-nitrophenyl)-5-oxo5,6,7,8-tetrahydro-4H-chromene-3-carbonitrile, Figure S21. ${ }^{1} \mathrm{HNMR}$ spectrum of 2-amino-4-(2chlorophenyl)-7,7-dimethyl-5-oxo-5,6,7,8-tetrahydro-4H-chromene-3-carbonitrile, Figure S22. ${ }^{1} \mathrm{HNMR}$ spectrum of 2-amino-4-(2,6-dichlorophenyl)-7,7-dimethyl-5-oxo-5,6,7,8-tetrahydro-4H-chromene3-carbonitrile.

Author Contributions: Conceptualization, S.S. and M.M.H.; methodology, F.K. and N.A.-D.; validation, F.K. and S.S.; formal analysis, F.K. and N.A.-D.; investigation; resources, S.S. and M.M.H.; data curation, F.K. and N.A.-D.; writing-original draft preparation, F.K. and S.S.; writing-review and editing S.S.; visualization, F.K. and N.A.-D.; supervision, S.S. and M.M.H.; project administration, S.S. and M.M.H.; funding acquisition, S.S. and M.M.H. All authors have read and agreed to the published version of the manuscript.

Funding: This research received no external funding.

Data Availability Statement: The data presented in this study are available in article.

Acknowledgments: The authors appreciate the partial support of Iran Polymer and Petrochemical Institute and Alzahra University.

Conflicts of Interest: The authors declare no conflict of interest.

\section{References}

1. Molnár, Á. The use of chitosan-based metal catalysts in organic transformations. Coord. Chem. Rev. 2019, 388, 126-171. [CrossRef]

2. Baruah, M.J.; Bora, T.J.; Dutta, R.; Roy, S.; Guha, A.K.; Bania, K.K. Fe(III) superoxide radicals in halloysite nanotubes for visible-light-assisted benzyl alcohol oxidation and oxidative CC coupling of 2-naphthol. Mol. Catal. 2021, 515, 111858. [CrossRef]

3. Sadjadi, S.; Koohestani, F. Composite of $\beta$-cyclodextrin and bentonite clay: A promising support for Pd immobilization and developing a catalyst for hydrogenation of nitroarenes under mild reaction condition. J. Phys. Chem. Solids 2021, 151, 109894. [CrossRef]

4. Daroughegi Mofrad, B.; Rezaei, M.; Hayati-Ashtiani, M. Preparation and characterization of Ni catalysts supported on pillared nanoporous bentonite powders for dry reforming reaction. Int. J. Hydrog. Energy 2019, 44, 27429-27444. [CrossRef]

5. Kanchana, U.S.; Diana, E.J.; Mathew, T.V.; Anilkumar, G. Cyclodextrin based palladium catalysts for Suzuki reaction: An overview. Carbohydr. Res. 2020, 489, 107954. [CrossRef] [PubMed]

6. Zolfigol, M.A.; Kiafar, M.; Yarie, M.; Taherpour, A.; Saeidi-Rad, M. Experimental and theoretical studies of the nanostructured $\left\{\mathrm{Fe}_{3} \mathrm{O}_{4} @ \mathrm{SiO}_{2} @\left(\mathrm{CH}_{2}\right)_{3} \mathrm{Im}\right\} \mathrm{C}(\mathrm{CN})_{3}$ catalyst for 2-amino-3-cyanopyridine preparation via an anomeric based oxidation. RSC Adv. 2016, 6, 50100-50111. [CrossRef]

7. Sharma, H.; Kaur, N.; Singh, N.; Jang, D.O. Synergetic catalytic effect of ionic liquids and ZnO nanoparticles on the selective synthesis of 1,2-disubstituted benzimidazoles using a ball-milling technique. Green Chem. 2015, 17, 4263-4270. [CrossRef]

8. Adamski, J.; Qadir, M.I.; Serna, J.P.; Bernardi, F.; Baptista, D.L.; Salles, B.R.; Novak, M.A.; Machado, G.; Dupont, J. Core-Shell Fe-Pt Nanoparticles in ionic liquids: Magnetic and catalytic properties. J. Phys. Chem. C 2018, 122, 4641-4650. [CrossRef]

9. Chaugule, A.A.; Tamboli, A.H.; Kim, H. Ionic liquid as a catalyst for utilization of carbon dioxide to production of linear and cyclic carbonate. Fuel 2017, 200, 316-332. [CrossRef]

10. Bobbink, F.D.; Dyson, P.J. Synthesis of carbonates and related compounds incorporating $\mathrm{CO}_{2}$ using ionic liquid-type catalysts: State-of-the-art and beyond. J. Catal. 2016, 343, 52-61. [CrossRef]

11. Sadjadi, S. Magnetic (poly) ionic liquids: A promising platform for green chemistry. J. Mol. Liqu. 2021, 323, 114994. [CrossRef] 
12. Karimi, F.; Zolfigol, M.A.; Yarie, M. A novel and reusable ionically tagged nanomagnetic catalyst: Application for the preparation of 2-amino-6-(2-oxo-2H-chromen-3-yl)-4-arylnicotinonitriles via vinylogous anomeric based oxidation. Mol. Catal. 2019, 463, 20-29. [CrossRef]

13. Teimuri-Mofrad, R.; Gholamhosseini-Nazari, M.; Payami, E.; Esmati, S. Ferrocene-tagged ionic liquid stabilized on silica-coated magnetic nanoparticles: Efficient catalyst for the synthesis of 2-amino-3-cyano-4H-pyran derivatives under solvent-free conditions. Appl. Organomet. Chem. 2018, 32, e3955. [CrossRef]

14. Rafiee, E.; Kahrizi, M. Mechanistic investigation of Heck reaction catalyzed by new catalytic system composed of $\mathrm{Fe}_{3} \mathrm{O}_{4} @ \mathrm{OA}-\mathrm{Pd}$ and ionic liquids as co-catalyst. J. Mol. Liq. 2016, 218, 625-631. [CrossRef]

15. Lei, S.; Luo, R.; Li, H.; Chen, J.; Zhong, J.; Li, J. Ionic liquid assisted in-situ construction of S-scheme BiOI/Bi $2 \mathrm{WO}_{6}$ heterojunctions with improved sunlight-driven photocatalytic performance. Inorg. Chem. Commun. 2020, 121, 108192. [CrossRef]

16. Alizadeh, A.; Fakhari, M.; Safaei, Z.; Khodeai, M.M.; Repo, E.; Asadi, A. Ionic liquid-decorated $\mathrm{Fe}_{3} \mathrm{O}_{4} @ \mathrm{SiO}_{2}$ nanocomposite coated on talc sheets: An efficient adsorbent for methylene blue in aqueous solution. Inorg. Chem. Commun. 2020, 121, 108204. [CrossRef]

17. Abo-Hamad, A.; AlSaadi, M.A.; Hayyan, M.; Juneidi, I.; Hashim, M.A. Ionic liquid-carbon nanomaterial hybrids for electrochemical sensor applications: A review. Electrochim. Acta 2016, 193, 321-343. [CrossRef]

18. Sadjadi, S.; Heravi, M.M.; Kazemi, S.S. Ionic liquid decorated chitosan hybridized with clay: A novel support for immobilizing Pd nanoparticles. Carbohyd. Polym. 2018, 200, 183-190. [CrossRef]

19. Sadjadi, S.; Koohestani, F. Functionalized chitosan polymerized with cyclodextrin decorated ionic liquid: Metal free and biocompatible catalyst for chemical transformations. Int. J. Biol. Macromol. 2020, 147, 399-407. [CrossRef]

20. Gildeh, S.F.G.; Roohi, H.; Mehrdad, M.; Rad-Moghadam, K.; Ghauri, K. Synthesis and characterization of dicationic and monocationic fluorine-containing DBU based ionic liquids: Experimental and quantum chemical approaches. J. Mol. Struct. 2021, 1245, 131123. [CrossRef]

21. Glotov, A.; Vutolkina, A.; Pimerzin, A.; Nedolivko, V.; Zasypalov, G.; Stytsenko, V.; Karakhanov, E.; Vinokurov, V. Ruthenium Catalysts Templated on Mesoporous MCM-41 type silica and natural clay nanotubes for hydrogenation of benzene to cyclohexane. Catalysts 2020, 10, 537. [CrossRef]

22. Karakhanov, E.; Maximov, A.; Zolotukhina, A.; Vinokurov, V.; Ivanov, E.; Glotov, A. Manganese and Cobalt Doped Hierarchical Mesoporous Halloysite-Based Catalysts for Selective Oxidation of p-Xylene to Terephthalic Acid. Catalysts 2020, 10, 7. [CrossRef]

23. Karimi, S.; Bahri-Laleh, N.; Pareras, G.; Sadjadi, S.; Nekoomanesh-Haghighi, M.; Poater, A. Pd on nitrogen rich polymer-halloysite nanocomposite as an environmentally benign and sustainable catalyst for hydrogenation of polyalfaolefin based lubricants. J. Ind. Eng. Chem. 2021, 97, 441-451. [CrossRef]

24. Yu, T.; Swientoniewski, L.T.; Omarova, M.; Li, M.-C.; Negulescu, I.I.; Jiang, N.; Darvish, O.A.; Panchal, A.; Blake, D.A.; Wu, Q.; et al. Investigation of Amphiphilic polypeptoid-functionalized halloysite nanotubes as emulsion stabilizer for oil spill remediation. ACS Appl. Mater. Interfaces 2019, 11, 27944-27953. [CrossRef] [PubMed]

25. Vinokurov, V.; Stavitskaya, A.; Glotov, A.; Ostudin, A.; Sosna, M.; Gushchin, P.; Darrat, Y.; Lvov, Y. Halloysite nanotube-based cobalt mesocatalysts for hydrogen production from sodium borohydride. J. Solid State Chem. 2018, 268, 182-189. [CrossRef]

26. Smith, R.J.; Holder, K.M.; Ruiz, S.; Hahn, W.; Song, Y.; Lvov, Y.M.; Grunlan, J.C. Environmentally benign halloysite nanotube multilayer assembly significantly reduces polyurethane flammability. Adv. Funct. Mater. 2018, 28, 1703289. [CrossRef]

27. Lazzara, G.; Cavallaro, G.; Panchal, A.; Fakhrullin, R.; Stavitskaya, A.; Vinokurov, V.; Lvov, Y. An assembly of organic-inorganic composites using halloysite clay nanotubes. Curr. Opin. Colloid Interface Sci. 2018, 35, 42-50. [CrossRef]

28. Cavallaro, G.; Chiappisi, L.; Pasbakhsh, P.; Gradzielski, M.; Lazzara, G. A structural comparison of halloysite nanotubes of different origin by Small-Angle Neutron Scattering (SANS) and Electric Birefringence. Appl. Clay Sci. 2018, 160, 71-80. [CrossRef]

29. Wang, H.; Wu, D.; Li, X.; Huo, P. Ce doping TiO2/halloysite nanotubes photocatalyst for enhanced electrons transfer and photocatalytic degradation of Tetracycline. J. Mater. Sci. Mater. Electron. 2019, 30, 19126-19136. [CrossRef]

30. Vinokurov, V.A.; Stavitskaya, A.V.; Ivanov, E.V.; Gushchin, P.A.; Kozlov, D.V.; Kurenkova, A.Y.; Kolinko, P.A.; Kozlova, E.A.; Lvov, Y.M. Halloysite Nanoclay Based CdS Formulations with high catalytic activity in hydrogen evolution reaction under visible light irradiation. ACS Sustain. Chem. Eng. 2017, 5, 11316-11323. [CrossRef]

31. Deng, L.; Yuan, P.; Liu, D.; Du, P.; Zhou, J.; Wei, Y.; Song, Y.; Liu, Y. Effects of calcination and acid treatment on improving benzene adsorption performance of halloysite. Appl. Clay Sci. 2019, 181, 105240. [CrossRef]

32. Zhang, X.; Zhang, Z.; Zeng, Z.; Du, S.; Liu, E. Superoleophobic graphene oxide/halloysite nanotube composite membranes for oil-water separation. Mater. Chem. Phys. 2021, 263, 124347. [CrossRef]

33. Kaze, C.R.; Venyite, P.; Nana, A.; Juvenal, D.N.; Tchakoute, H.K.; Rahier, H.; Kamseu, E.; Melo, U.C.; Leonelli, C. Meta-halloysite to improve compactness in iron-rich laterite-based alkali activated materials. Mater. Chem. Phys. 2020, 239, 122268. [CrossRef]

34. Ngulube, T.; Gumbo, J.R.; Masindi, V.; Maity, A. Preparation and characterisation of high performing magnesite-halloysite nanocomposite and its application in the removal of methylene blue dye. J. Mol. Struct. 2019, 1184, 389-399. [CrossRef]

35. Szczepanik, B.; Słomkiewicz, P.; Garnuszek, M.; Czech, K.; Banaś, D.; Kubala-Kukuś, A.; Stabrawa, I. The effect of chemical modification on the physico-chemical characteristics of halloysite: FTIR, XRF, and XRD studies. J. Mol. Struct. 2015, 1084, 16-22. [CrossRef]

36. Yuan, P.; Tan, D.; Annabi-Bergaya, F. Properties and applications of halloysite nanotubes: Recent research advances and future prospects. Appl. Clay Sci. 2015, 112-113, 75-93. [CrossRef] 
37. Deng, L.; Yuan, P.; Liu, D.; Annabi-Bergaya, F.; Zhou, J.; Chen, F.; Liu, Z. Effects of microstructure of clay minerals, montmorillonite, kaolinite and halloysite, on their benzene adsorption behaviors. Appl. Clay Sci. 2017, 143, 184-191. [CrossRef]

38. Wei, Y.; Yuan, P.; Liu, D.; Losic, D.; Tan, D.; Chen, F.; Liu, H.; Zhou, J.; Du, P.; Song, Y. Activation of natural halloysite nanotubes by introducing lanthanum oxycarbonate nanoparticles via co-calcination for outstanding phosphate removal. Chem. Commun. 2019, 55, 2110-2113. [CrossRef]

39. Massaro, M.; Lazzara, G.; Milioto, S.; Noto, R.; Riela, S. Covalently modified halloysite clay nanotubes: Synthesis, properties, biological and medical applications. J. Mater. Chem. B 2017, 5, 2867-2882. [CrossRef] [PubMed]

40. Massaro, M.; Colletti, C.G.; Buscemi, G.; Cataldo, S.; Guernelli, S.; Lazzara, G.; Liotta, L.F.; Parisi, F.; Pettignano, A.; Riela, S. Palladium nanoparticles immobilized on halloysite nanotubes covered by a multilayer network for catalytic applications. New $J$. Chem. 2018, 42, 13938-13947. [CrossRef]

41. Dehghani, S.; Sadjadi, S.; Bahri-Laleh, N.; Nekoomanesh-Haghighi, M.; Poater, A. Study of the effect of the ligand structure on the catalytic activity of Pd@ ligand decorated halloysite: Combination of experimental and computational studies. Appl. Organomet. Chem. 2019, 33, e4891. [CrossRef]

42. Massaro, M.; Colletti, C.G.; Lazzara, G.; Milioto, S.; Noto, R.; Riela, S. Halloysite nanotubes as support for metal-based catalysts. J. Mater. Chem. A 2017, 5, 13276-13293. [CrossRef]

43. Sadjadi, S.; Akbari, M.; Heravi, M.M. Palladated nanocomposite of halloysite -nitrogen doped porous carbon prepared from a novel cyano/nitrile-free task specific ionic liquid: As an efficient catalyst for hydrogenation. ACS Omega 2019, 4, 19442-19451. [CrossRef] [PubMed]

44. Khazaei, A.; Sarmasti, N.; Yousefi Seyf, J. Anchoring high density sulfonic acid based ionic liquid on the magnetic nano-magnetite $\left(\mathrm{Fe}_{3} \mathrm{O}_{4}\right)$, application to the synthesis of hexahydroquinoline derivatives. J. Mol. Liq. 2018, 262, 484-494. [CrossRef]

45. Aminkhani, A.; Talati, M.; Sharifi, R.; Chalabian, F.; Katouzian, F. Highly efficient one-pot three-component synthesis and antimicrobial activity of 2-Amino-4H-chromene derivatives. J. Heterocycl. Chem. 2019, 56, 1812-1819. [CrossRef]

46. Jeong, Y.-C.; Moloney, M.G. Antibacterial barbituric acid analogues inspired from natural 3-acyltetramic acids; synthesis, tautomerism and structure and physicochemical property-antibacterial activity relationships. Molecules 2015, 20, 3582-3627. [CrossRef] [PubMed]

47. Sokmen, B.B.; Ugras, S.; Sarikaya, H.Y.; Ugras, H.I.; Yanardag, R. Antibacterial, antiurease, and antioxidant activities of some arylidene barbiturates. Appl. Biochem. Biotechnol. 2013, 171, 2030-2039. [CrossRef]

48. Brahmachari, G.; Nurjamal, K. Ultrasound-assisted and trisodium citrate dihydrate-catalyzed green protocol for efficient and one-pot synthesis of substituted chromeno $\left[3^{\prime}, 4^{\prime}: 5,6\right]$ pyrano $[2,3-\mathrm{d}]$ pyrimidines at ambient conditions. Tetrahedron Lett. 2019, 60, 1904-1908. [CrossRef]

49. Mohamadpour, F. Visible light irradiation promoted catalyst-free and solvent-free synthesis of pyrano [2, 3-d] pyrimidine scaffolds at room temperature. J. Saudi Chem. Soc. 2020, 24, 636-641. [CrossRef]

50. Khumalo, M.R.; Maddila, S.N.; Maddila, S.; Jonnalagadda, S.B. A facile and one-pot synthesis of new tetrahydrobenzo [b] pyrans in water under microwave irradiation. BMC Chem. 2019, 13, 132. [CrossRef]

51. Bakherad, M.; Moosavi, F.; Keivanloo, A.; Doosti, R.; Moradian, E.; Armaghan, M. Catalyst-free green synthesis of tetrahydrobenzo [b] pyrans in magnetized water: Experimental aspects and molecular dynamics simulation. Res. Chem. Intermed. 2019, 45, 2981-2997. [CrossRef]

52. Elhamifar, D.; Ramazani, Z.; Norouzi, M.; Mirbagheri, R. Magnetic iron oxide/phenylsulfonic acid: A novel, efficient and recoverable nanocatalyst for green synthesis of tetrahydrobenzo [b] pyrans under ultrasonic conditions. J. Colloid Interface Sci. 2018, 511, 392-401. [CrossRef] [PubMed]

53. Ahankar, H.; Taghavi Fardood, S.; Ramazani, A. One-pot three-component synthesis of tetrahydrobenzo [b] pyrans in the presence of $\mathrm{Ni0}$. 5Cu0. 5Fe2O4 magnetic nanoparticles under microwave irradiation in solvent-free conditions. Iran. J. Catal. 2020, 10, 195-201.

54. Adibian, F.; Pourali, A.R.; Maleki, B.; Baghayeri, M.; Amiri, A. One-pot synthesis of dihydro-1H-indeno [1, 2-b] pyridines and tetrahydrobenzo $[\mathrm{b}]$ pyran derivatives using a new and efficient nanocomposite catalyst based on N-butylsulfonate-functionalized MMWCNTs-D-NH2. Polyhedron 2020, 175, 114179. [CrossRef]

55. Koohestani, F.; Sadjadi, S. Polyionic liquid decorated chitosan beads as versatile metal-free catalysts for catalyzing chemical reactions in aqueous media. J. Mol. Liqu. 2021, 334, 115754. [CrossRef]

56. Sadjadi, S.; Koohestani, F.; Heravi, M.M. Fabrication of a metal free catalyst for chemical reactions through decoration of chitosan with ionic liquid terminated dendritic moiety. Sci. Rep. 2020, 10, 19666. [CrossRef] [PubMed]

57. Sadjadi, S.; Akbari, M.; Léger, B.; Monflier, E.; Heravi, M.M. Eggplant-derived biochar-halloysite nanocomposite as supports of Pd nanoparticles for the catalytic hydrogenation of nitroarenes in the presence of cyclodextrin. ACS Sustain. Chem. Eng. 2019, 7 , 6720-6731. [CrossRef]

58. Bordeepong, S.; Bhongsuwan, D.; Pungrassami, T.; Bhongsuwan, T. Characterization of halloysite from Thung Yai District, nakhon Si thammarat province, in southern Thailand. Songklanakarin J. Sci. Technol 2011, 33, 599-607.

59. Zatta, L.; da Costa Gardolinski, J.E.F.; Wypych, F. Raw halloysite as reusable heterogeneous catalyst for esterification of lauric acid. Appl. Clay Scie. 2011, 51, 165-169. [CrossRef] 
60. Maleki, B.; Ashrafi, S.S. Nano $\alpha-\mathrm{Al}_{2} \mathrm{O}_{3}$ supported ammonium dihydrogen phosphate $\left(\mathrm{NH}_{4} \mathrm{H}_{2} \mathrm{PO}_{4} / \mathrm{Al}_{2} \mathrm{O}_{3}\right)$ : Preparation, characterization and its application as a novel and heterogeneous catalyst for the one-pot synthesis of tetrahydrobenzo [b] pyran and pyrano [2, 3-c] pyrazole derivatives. RSC Adv. 2014, 4, 42873-42891. [CrossRef]

61. Rathod, S.; Arbad, B.; Lande, M. Preparation, characterization, and catalytic application of a nanosized $\mathrm{Ce}_{1 \mathrm{MgxZ}} \mathrm{r} 1-\mathrm{xO} \mathrm{O}_{2} \mathrm{Solid}$ heterogeneous catalyst for the synthesis of tetrahydrobenzo [b] pyran derivatives. Chin. J. Catal. 2010, 31, 631-636. [CrossRef]

62. Zaharani, L.; Khaligh, N.G.; Mihankhah, T.; Johan, M.R. Application of nitrogen-rich porous organic polymer for the solid-phase synthesis of 2-amino-4 H-benzo [b] pyran scaffolds using ball milling process. Mol. Divers. 2021, 25, 323-332. [CrossRef] [PubMed]

63. Mohammadi, P.; Sheibani, H. Synthesis and characterization of $\mathrm{Fe}_{3} \mathrm{O}_{4} @ \mathrm{SiO}_{2}$ guanidine-poly acrylic acid nanocatalyst and using it for one-pot synthesis of $4 \mathrm{H}$-benzo [b] pyrans and dihydropyrano [c] chromenes in water. Mater. Chem. Phys. 2019, 228, 140-146. [CrossRef]

64. Joshi, V.M.; Magar, R.L.; Throat, P.B.; Tekale, S.U.; Patil, B.R.; Kale, M.P.; Pawar, R.P. Novel one-pot synthesis of 4H-chromene derivatives using amino functionalized silica gel catalyst. Chin. Chem. Lett. 2014, 25, 455-458. [CrossRef]

65. Mozafari, R.; Heidarizadeh, F. Phosphotungstic acid supported on $\mathrm{SiO}_{2} @ \mathrm{NHPhNH}_{2}$ functionalized nanoparticles of $\mathrm{MnFe}_{2} \mathrm{O}_{4}$ as a recyclable catalyst for the preparation of tetrahydrobenzo [b] pyran and indazolo [2, 1-b] phthalazine-triones. Polyhedron 2019, 162, 263-276. [CrossRef]

66. Bhattacharyya, P.; Pradhan, K.; Paul, S.; Das, A.R. Nano crystalline ZnO catalyzed one pot multicomponent reaction for an easy access of fully decorated $4 \mathrm{H}$-pyran scaffolds and its rearrangement to 2-pyridone nucleus in aqueous media. Tetrahedron Lett. 2012, 53, 4687-4691. [CrossRef]

67. Thanaraj, C.; Priya Dharsini, G.; Ananthan, N.; Velladurai, R. Facile route for the synthesis and cytotoxic effect of 2-amino-4 $\mathrm{H}$-benzo $[\mathrm{b}]$ pyran derivatives in aqueous media using copper oxide nanoparticles decorated on cellulose nanocrystals as heterogeneous catalyst. Inorg. Nano-Met. Chem. 2019, 49, 313-321. [CrossRef]

68. Hasaninejad, A.; Shekouhy, M.; Golzar, N.; Zare, A.; Doroodmand, M.M. Silica bonded n-propyl-4-aza-1-azoniabicyclo [2.2. 2] octane chloride (SB-DABCO): A highly efficient, reusable and new heterogeneous catalyst for the synthesis of $4 \mathrm{H}-$ benzo [b] pyran derivatives. Appl. Catal. A Gen. 2011, 402, 11-22. [CrossRef] 